
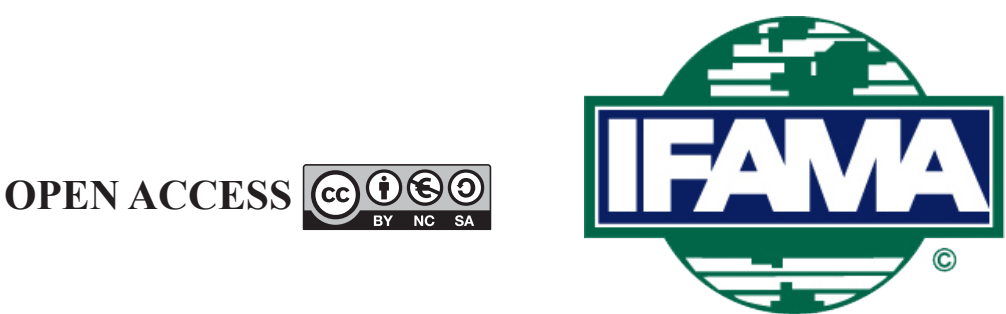

International Food and Agribusiness Management Review

Volume 25, Issue 1, 2022; DOI: 10.22434/IFAMR2020.0187

Received: 29 October 2020 / Accepted: 23 March 2021

\title{
Improving decision-making through material flow cost accounting: the case of VietGreen bottled mineral water company \\ CASE STUDY
}

\author{
Thuy Thanh Tran ${ }^{\circledR a}$,b and Christian Herzig ${ }^{c}$ \\ ${ }^{a}$ Lecturer, School of Accounting, University of Economics Ho Chi Minh City, \\ 59C Nguyen Dinh Chieu Street, District 3, Ho Chi Minh City, 70000, Vietnam \\ ${ }^{b}$ Researcher, ${ }^{c}$ Professor, Management in the International Food Industry, \\ University of Kassel, Steinstrasse 19, Witzenhausen, 37213, Germany
}

\begin{abstract}
VietGreen, headquartered in the South of Vietnam, is a bottled mineral water company striving towards becoming a leading mineral water producer with a strong reputation for social responsibility and integrity. This case describes VietGreen's decision to explore the potential of material flow cost accounting (MFCA) for enhanced eco-efficiency and achieving the company's long-term goals. It introduces the students to the company's major challenges in meeting existing and newly introduced environmental regulations and in dealing with various controversial perspectives of managers involved in a project to implement MFCA. The focal questions of the case are why and how the company's management should invest in and apply MFCA to implement its major strategic objectives. In particular, it focuses on the tension between measures improving either environmental or economic performance as well as the search for solutions contributing to both types of goals.
\end{abstract}

Keywords: bottled mineral water production, economic and environmental performance, eco-efficiency, material flow cost accounting, decision-making

JEL code: Q56

\footnotetext{
(i)Corresponding author: tranthanhthuy@ueh.edu.vn; thuy.tran@uni-kassel.de
} 
I was concerned about corporate performance in the coming years. The company was facing some considerable challenges in accomplishing its economic and environmental goals. The year 2018 was daunting for VietGreen since we were forced to make totally unprecedented decisions in the last ten years. (Minh Le, Chief Executive Officer, June 17 ${ }^{\text {th }}, 2018$ )

\section{Introduction}

In 2008, the VietGreen Mineral Water Company was established by Mai Tran, a business owner and environmental engineer. Six months later, the bottling plant was built in south Vietnam, where the source of mineral water was found. The company invested over one million USD in purchasing manufacturing equipment and building this factory with an area of 3,500 square meters. At the end of 2017, Mai Tran developed a new vision, strategic objectives, and core values for the company. The new vision was: 'VietGreen will become the best mineral water brand in Vietnam in 2025 and will be one of the top 30 mineral water brands in the world by 2030'. Based on this vision, the new strategic objectives were made from different perspectives, such as developing new products with a diversity of bottle sizes and tastes, implementing continuous improvement, and achieving sustainable growth. To accomplish the above goals, the new core values were emphasized: 'integrity, responsibility, and diversity'.

In recent years, new environmental legislation, including a national technical regulation on industrial wastewater ${ }^{1}$ and a regulation on environmental protection fees for industrial wastewater ${ }^{2}$, put pressure on companies in the bottled water industry. The appearance of new regulations confronted VietGreen with economic and environmental considerations, as the company did not own a wastewater treatment system when it was starting to pursue its long-term strategies. In 2018, Minh Le, the determined and dedicated Chief Executive Officer (CEO) of the company, decided to establish a material flow cost accounting project and arranged three roundtable meetings to ascertain what the company should improve, thereby achieving high efficiency in future investments.

\section{The bottled water industry}

\subsection{Consumption of bottled water}

The origins of the bottled water industry in Europe go back to the middle of the $16^{\text {th }}$ century. ${ }^{3}$ The consumption of bottled water has been on the rise due to considerations for health, safety, purity, taste, and convenience. In the recent past, global bottled water consumption grew by $6.4 \%$ (compound annual growth rate) from over 70,000 million gallons in 2012 to nearly 100,000 million gallons in 2017. This trend of increasing consumption occurred across the globe. It experienced a dramatic increase throughout Asian countries, especially in China, with the highest rate of $11.8 \%$ among the ten biggest bottled water markets, followed by Indonesia (10.4\%), and India (9.7\%). China led the market in bottled water consumption with the equivalent of more than 25,000 million gallons, followed by the United States with the equivalent of more than 13,000 million gallons in 2017 (Supplementary Table S1). The average per capita bottled water consumption of all countries was 13.2 gallons. Mexico, Thailand, and Italy had the biggest per capita consumption rates with 67.2 gallons, 57.5 gallons, and 48.2 gallons, respectively (Supplementary Table S2).

As compared with other countries, the bottled water consumption of Vietnam was not high, at 320.04 million gallons (1,211.5 million liters) in 2017. The average per capita consumption saw a slight increase, from 3.09 gallons (11.7 liters) in 2016 to 3.41 gallons (12.9 liters) in 2017 (Supplementary Table S3). Leaders of the bottled water market in Vietnam were international companies (Suntory PepsiCo Vietnam Beverage, La Vie, and Coca-Cola Beverages Vietnam), which accounted for two thirds of off-trade value sales. In particular,

\footnotetext{
${ }^{1}$ QCVN 40:2011/BTNMT - National Technical Regulation on Industrial Wastewater

2 154/2016/NĐ-CP - Regulation on Environmental Protection Fees for Industrial Wastewater

${ }^{3} \mathrm{https}$ //naturalmineralwaterseurope.org/water/history-of-natural-mineral-water/
} 
Suntory PepsiCo Vietnam Beverage continued to lead the sale of bottled water in both carbonated and still bottled water ${ }^{4}$.

\subsection{Three types of bottled water}

According to the European Federation of Bottled Water $(\mathrm{EFBW})^{5}$, which is a non-profit international trade association composed of national associations and bottled water companies across Europe, bottled water is divided into three types: natural mineral water, spring water, and bottled drinking water. Natural mineral water has a distinctive mineral composition that depends on the water source and brand. This composition includes a wide variety of minerals, such as calcium, fluoride, magnesium, and nitrate. The amount of minerals dissolved in water is indicated as total dissolved solids (TDS), which can be measured as milligrams per liter (mg/l) or parts per million (ppm). According to the International Bottled Water Association (IBWA ${ }^{6}$, mineral water is water that contains no less than $250 \mathrm{ppm}$ TDS. Moreover, it is distinguished from other types of bottled water 'by its constant level and relative proportions of mineral and trace elements at the point of emergence from the source. No minerals can be added to this product'. In contrast, spring water does not require a stable mineral balance and presents information about mineral composition on the label, although it needs to be exploited from an underground source and assured to be microbiologically safe. While both natural mineral water and spring water originate from underground water sources without any chemical treatment, bottled drinking water is often treated and disinfected for taste.

\section{The production process}

In early 2010, the company officially began to operate its production process. Still mineral water is bottled in one size (0.5 liters) and is distributed to big cities in Vietnam, such as Hanoi, Da Nang, and Ho Chi Minh City. The production of bottled mineral water strictly follows both international (e.g. ISO 9001:2015) and national standards (e.g. QCVN 09:2015/BTNMT) ${ }^{7}$. Most direct laborers of VietGreen's production steps are local residents. The production process includes three main steps (water filtering, bottle filling and cap closing, labelling and packaging) and a supportive process (bottle and cap cleaning). All steps use electric energy to operate related manufacturing activities and include further inputs and outputs, as described in the following steps.

\subsection{Step 1: water filtering}

Raw mineral water is directly transported from the source of mineral water through stainless steel pipes into the factory. Information about the received water in storage tanks is monitored on a daily basis. Then, the process of filtering is completed to remove suspended matter, color, odor, smell, and micron-sized particles from the water. After that, a water softener is used to reduce water hardness before the process of disinfection by an ultra-violet system. Auxiliaries, which are necessary materials to support filtration and disinfection, are controlled on a monthly basis. There is a small amount of wastewater and normal solid waste at this stage.

\subsection{Step 2: bottle filling and cap closing}

The large room used for bottle filling and cap closing is highly sanitary to ensure the safety of the process. First, clean empty bottles are automatically moved from the cleaning system to the bottle filling system. Next, nozzles pour the filtered mineral water into the bottles held by grippers. Then, clean bottle caps from the cleaning system, which uses chemicals and groundwater to ensure the hygiene and safety of empty bottles and caps, are transported and pressed onto the filled bottles. Finally, the quality of filled and capped bottles is checked by the manufacturing workers before being labelled and packaged. Wastewater is released

\footnotetext{
${ }^{4}$ https://www.euromonitor.com/bottled-water-in-vietnam/report

5 https://www.efbw.org/index.php?id=40

${ }^{6}$ https://www.bottledwater.org/types/bottled-water

${ }^{7}$ QCVN 09:2015/BTNMT - National Technical Regulation on Ground Water Quality
} 
from both the main step of bottle filling and cap closing, as well as in the supportive process of bottle and cap cleaning. Also, craps are collected at the bottle filling stage, while toxic solid waste is collected at the bottle and cap cleaning stage.

\subsection{Step 3: labelling and packaging}

Each bottle is labelled with sufficient information about the company and its mineral ingredients. A steam system is used to heat shrink wrap and label the bottles. On the cap of each bottle, the exact date of bottling is printed. Most of the waste from the labelling and packaging step is printing ink boxes (toxic solid waste) and the packages of shrink wrap and sticky tape (normal solid waste). All finished bottles are finally packed into cartons to prepare for shipment to the domestic market.

\section{Material flow cost accounting project}

In 2018, VietGreen was challenged to meet new environmental regulations and achieve the company's major objectives. At that time, Minh Le (CEO) attended a workshop organized by the Vietnam Productivity Institute in which a trainer introduced a new concept called material flow cost accounting (MFCA).

\subsection{Definition of material flow cost accounting}

MFCA is 'one of the major tools for environmental management accounting and promotes increased transparency of material use practices through the development of a material flow model that traces and quantifies the flows and stocks of materials within an organization in physical and monetary units' (APO, 2014: 1). MFCA requires information concerning material and energy flow accounting (physical units), material and energy cost accounting (monetary units), and monetary environmental investment appraisal (monetary units).

Material and energy flow accounting requires the tracking of all inputs and outputs (materials, energy, products, non-products) in physical units, such as $\mathrm{kg}, \mathrm{kWh}$, and $\mathrm{m}^{3}$. A flowchart of the main production steps and supportive processes is commonly used to depict a production system, thereby preparing input and output tables.

Material and energy cost accounting refers to all costs that cause environmental impacts. For example, the purchasing costs of energy, water, and other materials become non-product outputs. Drawing from physical information, the company could identify and differentiate between all costs associated with 'products' and 'material losses' and determine where environmentally induced costs originate.

Monetary environmental investment appraisal is a powerful tool to solve corporate environmental issues with a long-term focus. Based on physical and monetary information in terms of material and energy perspectives, the company could pinpoint hotpots of the production process where material losses could be reduced, thereby identifying solutions to increase both economic and environmental performance.

\subsection{Development and benefits of material flow cost accounting}

MFCA is an internationally standardized approach in ISO 14051, 14052, and 14053 (Christ and Burritt, 2016; ISO, 2011, 2017, 2021). The approach has been increasingly used around the globe, including both developed countries (e.g. Germany and Japan (METI, 2010; Wagner, 2015)) and developing countries (e.g. Vietnam, Thailand, and the Philippines (Herzig et al., 2012; Tran and Herzig, 2020)). It can help companies enhance both economic and environmental performance (Guenther et al., 2015; Kokubu and Nakajima, 2004). Since 2010, the use of MFCA in Vietnam has been strongly supported by the Vietnamese Ministry 
of Science and Technology through a 712 National Productivity Program. ${ }^{8}$ The successful result of this program was presented in a public document in Vietnamese called 'Material flow cost accounting: basic content and applied guideline', , showing typical MFCA examples in different industries, such as beverage, seafood, vegetable, and fruit processing.

\subsection{Decision on VietGreen's material flow cost accounting project team}

Minh Le learned more about the benefits of MFCA through practical case studies presented in the workshop organized by the Vietnam Productivity Institute. After the workshop, Minh Le thought that the approach could be used to help VietGreen identify losses and make continuous improvements. Therefore, he decided to establish a project team to explore the potential of MFCA for enhanced eco-efficiency to achieve the company's long-term goals. As a leader of the project, he needed to select members of the team to economize production costs. Before three roundtable meetings were organized and detailed actions were taken, he required managers to provide some constructive information about cost savings, waste reduction, and market expansion. Some suggestions and feedback were:

We should look for new suppliers to save on material costs. Currently, we are applying the payment policy within 31-60 days. We could negotiate with current suppliers to have a better price if we could adopt a new payment policy that is within 30 days. (Lan Nguyen, purchasing department manager)

I was considering solutions to reduce the large volume of wastewater and craps at the bottle filling and cap closing stage. I am worried about the increasing amount of wastewater and toxic solid water at the stage of bottle and cap cleaning. (Tai Pham, environment department manager)

The company sold 94,650,000 mineral water bottles to the domestic market in 2017 . We should have a bigger budget for running our new marketing strategy with the new slogan - 'making the environment cleaner, making people healthier, and making life better.' (Linh Nguyen, sales and marketing department manager)

\section{Material and energy flow accounting}

\subsection{The first meeting: opening presentation}

After the MFCA team was established (Supplementary Table S4), selected managers of the project team were invited to the first meeting. At 8:00 am, Minh Le (CEO) gave an opening presentation regarding the importance of the MFCA approach and the meeting agenda. After that, he explained the reasons why the company should adopt this new approach:

I participated in a workshop organized by the Vietnam Productivity Institute that introduced a new management approach to me, MFCA. I think that this approach is compatible with the company's long-term objectives. Thank you so much for the suggestions and feedback that you sent me last week. They show that there are many problems taking place that should be addressed. Today, I would like to listen to your presentations in more detail. Then, together we will analyze the usefulness of material and energy flow accounting for improving the company's production process.

\subsection{The first meeting: reporting and discussion}

To continue, Long Hoang, a production manager with over 20 years of experience, was invited to report on the company's manufacturing position in 2017. He stated that:

\footnotetext{
${ }^{8}$ https://www.most.gov.vn/vn/Pages/ChiTietVanBan.aspx?vID=28407\&TypeVB=1 (in Vietnamese)

9 https://tcvn.gov.vn/wp-content/uploads/2019/03/17.-LVP-66A-T12.2018.-88t-Sach-MFCA-Final-20.12-mi.pdf (in Vietnamese)
} 
Our production was very good. We always ensure the quantity of products due to manufacturing activities with continuous production - 24 hours per day. In 2017, direct laborers worked 316 days. We monitored the quality of mineral water on a daily basis to meet customers' high standards. With each manufacturing period (eight hours), we allocated a number of direct laborers as follows: four laborers working at the stage of water filtering, six laborers working at the stage of bottle filling and cap closing, two laborers working at the stage of bottle and cap cleaning, and seven laborers working at the stage of labelling and packaging.

Next, Bao Tran, the warehouse manager, presented information about the inputs such as chemicals, labelling and packaging materials, and auxiliaries used in the production process (Supplementary Table S5). He highlighted that all goods were strictly checked and controlled at three warehouses, including the first warehouse for storing final products, the second warehouse for storing empty bottles, caps, and auxiliaries, and the third warehouse for storing chemicals. He provided further information about the inventory, which included 1,340,400 final bottles at the beginning of 2017 and 290,400 final bottles at the end of 2017. In addition, there were 100,152,000 empty bottles and 93,600,000 bottle caps, which were transported to the process of bottle and cap cleaning and were cleaned in 2017. The weight of each empty bottle was 19 grams, and the weight of each bottle cap was 1.8 grams. To clearly understand the usage of electric energy and water, a report was carefully prepared by Ha Bui, who is responsible for the activities of the utility department. According to her evaluation, the consumption of electricity, water, and steam was quite stable and well controlled. The company used electricity with a low tension $(<6 \mathrm{KV})$ within the production process (Supplementary Table S6).

After that, Tai Pham from the environment department, a young and new engineer, presented some challenging problems concerning waste. Also, he reported wastewater, solid waste, and the pollution volume in wastewater (Supplementary Tables S7 and S8). He emphasized that a detailed report about managing solid waste and wastewater was sent quarterly to the Province Department of Natural Resources and Environment.

At 11:00 am, in line with their presentations, a discussion took place.

According to my calculations, there was $30,177 \mathrm{~m}^{3}$ of wastewater arising from all production processes in the amount of $8,193 \mathrm{~m}^{3}, 7,625 \mathrm{~m}^{3}, 6,815 \mathrm{~m}^{3}$, and 7,544 $\mathrm{m}^{3}$ for the first, second, third, and last quarter, respectively. I am concerned about the company's wastewater. (Tai Pham, environment department manager)

I think that we should concentrate on the marketing strategy to increase profits and expand into new markets. Customers drink mineral water because it is good for their health. They do not care about wastewater. Our wastewater has met the basic conditions to be released into the environment. We should not waste time discussing environmental problems. He looked at Tai Pham and concluded, 'You are only a new employee of the company'. (Linh Nguyen, sales and marketing department manager)

You are right, Linh Nguyen. The environmental problems are not as serious as Tai Pham said. I have been engaged with this company since it was established. I clearly know what we did in the past. The manufacturing process is well controlled and efficient. We need to save on expenses for the company. If the company wants to address the wastewater problem, we could invest in a new system of wastewater treatment, which is very simple. (Long Hoang, production department manager)

I completely disagree with Long Hoang. Production costs increased roughly 10\% in 2017 as compared with 2016. This led to a decrease in profits in the last year. I do not think that it is simple to make a new budget for investing in wastewater treatment. Furthermore, if the new strategy of the company is implemented, marketing costs and costs for designing new products might continue to increase. (Ly Pham, accounting department manager) 
I think that we should focus on environmental concerns if the company's strategy is to develop sustainably. Every quarter, polluted emissions within the company's industrial wastewater were measured and reported to be level B quality by a reliable service. Although our wastewater meets regulatory requirements to release into the environment, we should aim to improve its quality and reduce the level of pollution. I was considering the higher standard (level A quality) of wastewater ${ }^{10}$ proposed by the Ministry of Natural Resources and Environment. Accordingly, the levels allowed for COD (chemical oxygen demand), $\mathrm{Pb}$ (lead), and Cd (cadmium) are 75, 0.1, and $0.05 \mathrm{mg} / 1$, respectively. (Tai Pham, environment department manager)

\subsection{The first meeting: analysis of material and energy flow accounting}

The atmosphere of the meeting became fairly strained when there were controversial ideas from heads of departments. However, it was 12:00 noon. According to the agenda of the meeting, it took about 60 minutes to have lunch and people came back at 1:00 pm.

After lunch, Minh Le started to share his thoughts:

Our task today is to analyze material and energy flows related to our production process. As far as I know, this analysis will help us to identify inefficiencies and their causes. Instead of arguing whether a marketing strategy or a wastewater treatment system investment is better for us, let us first consult our flowchart and start filling in physical information, including incorporating items, physical units, data sources, and amounts into input/output tables.

\section{Material and energy cost accounting}

\subsection{The second meeting: opening presentation}

Based on the analysis of material and energy flow accounting, the second meeting was organized to calculate and discuss the results of related costs by using the MFCA approach. At 8:00 am, Minh Le (CEO) explained the difference between conventional cost accounting and material and energy flow cost accounting. He emphasized that:

VietGreen is applying conventional cost accounting to calculate the total product costs. These costs include direct costs and indirect costs (overhead costs). Waste costs are one of the indirect costs. Although the company recorded waste costs, these costs were hidden in overhead accounts. With MFCA, the company could calculate environmentally induced costs towards each process and trace back to where they originated.

\subsection{The second meeting: reporting and discussion}

After that, Tai Pham (environment department manager) reported the costs related to non-product outputs, including wastewater and solid waste.

In 2016, a new regulation on environmental protection fees for industrial wastewater ${ }^{11}$ was also promulgated. From this, the environment department was responsible for quarterly reporting on environmental protection fees. The arising fees of the company include a fixed fee (66.079 USD per year) and a variable fee depending on total wastewater and the amount of parameter in wastewater analysis (Supplementary Table S9).

${ }^{10}$ QCVN 40:2011/BTNMT - National Technical Regulation on Industrial Wastewater

11 154/2016/NĐ-CP - Regulation on Environmental Protection Fees for Industrial Wastewater 
The Vietnamese government passed a regulation ${ }^{12}$ on solid waste management, including both toxic solid waste and normal solid waste. Compliant with the regulation, the company proposed helpful guidelines about how to collect, categorize, and transport all industrial solid waste to safe areas. They were clearly labelled and recorded according to each manufacturing process. The cost of toxic solid waste was $0.696 \mathrm{USD} / \mathrm{kg}$ in 2017. In addition, there was a commercial contract between the company and the waste service company on a yearly basis, in which the company received income from selling craps and normal solid waste at the price of $0.040 \mathrm{USD} / \mathrm{kg}$.

To continue, Lan Nguyen (purchasing department manager) added further information about purchasing costs associated with PET bottles and other materials:

Currently, the company purchases PET bottles and caps from local suppliers. There are two different types of prices based on payment time. The price of PET bottles is 0.053 USD per empty bottle if the payment is implemented within 31-60 days. However, if the payment is implemented in fewer than 30 days, the price is 0.046 USD per empty bottle. Additionally, I would like to provide further information associated with the accepted price of some materials and auxiliaries. (Supplementary Table S10)

Then, Ly Pham (accounting department manager) presented other related manufacturing costs, including the cost of electricity, cost of water, and salary of direct laborers.

Based on the decisions on electricity price proposed by the Vietnamese Ministry of Industry and Trade ${ }^{13}$, Ly Pham summarized and prepared a detailed report (Supplementary Table S11). Further information was added that the price of steam was at $0.053 \mathrm{USD} / \mathrm{kg}$ in 2017 . In addition, an explanation of calculating water costs was presented at this meeting. Water costs were the amount of natural resource taxes that the company had to pay to the government for using water resources (Supplementary Table S12).

In 2014, Vietnam continued to demonstrate an interest in building up the green economy by launching the Law on Environmental Protection ${ }^{14}$. As a result, a new regulation ${ }^{15}$ on environmental protection fees for exploiting minerals was publicly announced in 2016 to related manufacturers. With regard to this regulation, mineral water experienced an increase in input costs. It was noted that VietGreen had to spend additional money to exploit mineral water from national water resources ( 0.132 USD per $\mathrm{m}^{3}$ of mineral water).

Over many years, the company has created valuable working opportunities for local residents. For instance, nearly $95 \%$ of manufacturing workers were employed from the available human resources of the province. Their salary was paid on a working-hour basis. In 2017, the total number of employees and managers working for the company was 270 people. Of these employees, $74 \%$ were male and $26 \%$ were female. To ensure monitoring of the quality of mineral water, from the beginning of its establishment, the company employed qualified engineers who had a wealth of knowledge about mechanics, chemicals, and the functioning ability of filtering systems. Their salary was higher than that of other workers who were responsible for the process of bottle filling and cap closing, bottle and cap cleaning, and labelling and packaging (Supplementary Table S13).

\subsection{The second meeting: analysis of material and energy cost accounting}

The second meeting lasted for over three hours. Afterwards, all necessary information for calculation was provided. Although Ly Pham had over ten years of work experience in accounting, it was the first time that she applied an MFCA approach to calculating production costs. She said that:

\footnotetext{
12 38/2015/NĐ-CP - Regulation on Solid Waste Management

13 http://www.moit.gov.vn/ (in Vietnamese)

14 55/2014/QH13 - Law on Environmental Protection

15 164/NĐ-CP - Regulation on Environmental Protection Fees for Exploiting Mineral
} 
I am considering allocating electricity and labor costs at the rate of $60 \%$ for the bottle filling step and $40 \%$ for the cap closing step. Thanks to physical information from Ha Bui (utility department manager), I have additional information on the stage of bottle filling, showing that the consumption of electricity and usage of direct labor to create craps is equal to that used to create wastewater.

Indeed, it was a challenging task for her to identify both product and non-product costs for each process. In terms of the MFCA approach, she was also expected to identify actual losses such as material loss and energy loss, which represent the main incentives for continuous improvement. Based on these, they could consider potential proposals to improve the company's performance.

\section{Monetary environmental investment appraisal}

\subsection{The third meeting: opening presentation}

After the process of material and energy flow analysis, as well as the calculation of related costs using the MFCA approach, the project team was faced with the considerable challenge of allocating funds among a range of compelling investment projects. To make final decisions, the third meeting was properly organized to discuss the three proposals based on the analysis of physical and monetary information discussed in the two previous meetings. These proposals were proposed by the environment and production departments.

At the beginning of the meeting, Minh Le (CEO) emphasized VietGreen's new vision and new strategic objectives again. He was expecting that new investments, which were decided by most of the managers, could be a promising future for the company. He said that:

As you know, in early February 2018, we replaced a system of producing steam from fossil fuels by directly purchasing steam from a reliable local supplier. Indeed, this replacement helped the company to generate cost savings and had a positive impact on the environment due to using a source of clean and efficient energy. This was true when the company was pursuing both economic and environmental performance. However, our funds and resources are limited and we must budget for new product introduction and market expansion; therefore, we should attentively rank the proposals.

To provide a clearer picture of the company's capital budget for a five-year period (2018-2022), Minh Le posited a spending limit on capital projects of only 220,000 USD for each year. Until June $30^{\text {th }}, 2018$, the company had successfully conducted two projects with a total amount of 148,942 USD. He also added major information:

The actual results of previous projects made a good contribution to the company's economic performance. I expect that the final decision will be made from the three potential proposals, which were suggested by the environment and production departments. Nonetheless, I would like to highlight that economic performance should be prioritized. The company needs money to exist and operate. I suggest that the discount rate of the company be $10 \%$.

\subsection{The third meeting: presentation of three proposals}

The following three proposals were presented at the meeting:

\section{- Proposal 1: a new system for wastewater treatment}

Wastewater treatment relates to a combination of physical, chemical, and biological processes to remove the suspended solids, organic matter, and nutrients from wastewater ${ }^{16}$ before the remaining water, called effluent, is released into the environment. The main by-product of wastewater treatment is sewage sludge.

\footnotetext{
$\overline{16}$ http://www.fao.org/3/t0551e/t0551e05.htm
} 
In late June 2018, Tai Pham (environment department manager) attended an important workshop in which modern technologies for wastewater treatment were introduced. During this workshop, he also received some informal information from an expert that there would be a dramatic increase in environmental protection fees in the coming years. Therefore, he strove to understand and analyze popular solutions for wastewater treatment. Then, he discussed the issue with employees within the environment department.

After considering some major factors, they found an experienced service supplier that could help the company to address the high rate of $\mathrm{COD}, \mathrm{Pb}$, and $\mathrm{Cd}$ in the company's wastewater. At the meeting, he explained the operation process of the wastewater treatment system. After that, he reported the estimated costs (Supplementary Table S14) and showed environmental results for wastewater if a new treatment system would be equipped (Supplementary Table S15). It is clear that the quality of wastewater would be improved, and the sludge would meet the standard of the National Technical Regulation on Hazardous Thresholds for Sludge from Water Treatment Process. ${ }^{17}$

\section{- Proposal 2: a new process for producing PET bottles}

PET plastic is the main packaging material used for mineral water due to its safety and convenience. Nonetheless, PET bottle costs accounted for a large portion of production costs. Therefore, bottled mineral water manufacturers have made an effort to reduce the weight of plastic bottles. For example, in 2009, Nestle Waters launched a new version of its Eco-Shape PET bottle with a reduction in bottle weight from 12.5 grams to 9.5 grams, which delivered a savings of 80 million pounds annually for the corporation. ${ }^{18}$ According to the International Bottled Water Association (IBWA), the average PET bottled water container weighed 18.9 grams in 2000 and 12.7 grams in 2008. There was a dramatic decrease in the weight of each PET bottle, leading to a savings of more than 1.3 billion pounds of PET plastic. ${ }^{19}$

In line with VietGreen's new strategy, the production department made an innovative plan to achieve its goal of plastic reduction. This goal could be accomplished by purchasing and equipping a new system for producing PET bottles. Long Hoang (production department manager) expected that the weight of PET plastic would be reduced to 10 grams with the new system. In addition, he described in detail the process of manufacturing PET bottles. To provide useful information for the proposal, he collaborated with the manager of the accounting department to calculate potential costs. As a result, he showed that the estimated cost of one PET bottle would be 0.039 USD. With this proposal, the company would strictly manage the quality of bottles and would become active in its manufacturing activities. However, the company would spend about $110,132.159$ USD on purchasing and installing the machines.

\section{- Proposal 3: a new system for the bottle filling process}

Along with the PET bottle proposal, the production department recommended an efficient solution to address the problem associated with the bottle filling process. The old system, which wasted time, water, electricity, and labor hours due to breakdown, could be sold in the first year of this project at the price of 5,286.344 USD. The new system would be set up to suit the company's various requirements, for example, the ability of flexible filling from $250 \mathrm{ml}$ to 51 bottles. It could strictly control input, output, bottle size, and system speed through a modern controller program and easily integrate the cap closing process in which there is no wastewater. In addition, wastewater and craps would be completely eliminated when it comes to bottle filling process.

Before presenting the investment costs (Supplementary Table S16), Long Hoang (production department manager) emphasized that:

\footnotetext{
17 QCVN 50:2013/BTNMT - The standard of the National Technical Regulation on Hazardous Thresholds for Sludge from Water Treatment Process

$18 \mathrm{https} / / / \mathrm{www} \cdot$ beveragedaily.com/Article/2009/12/17/Nestle-launches-lightweight-PET-bottle

$19 \mathrm{https} / /$ bottledwater.org/nr/weight-of-pet-bottled-water-containers-has-decreased-32-6-over-past-eight-years-saving-1-3-billon-lbs-of-plastic-resin/
} 
We searched for information and requested quotations from famous filling machine suppliers in Europe. Finally, we discussed and agreed to choose the supplier from Italy because of cost efficiency, productivity, quality assurance, and low maintenance. I think that we should invest in the new system since it would be compatible with the company's new strategy. If market demands increase, we need to assure the provision of high quality mineral water in time. Please look forward and think longterm, instead of just the short-term.

\subsection{The third meeting: investment decision-making}

After the three proposals were presented in detail, Lan Nguyen (purchasing department manager) argued that:

In my opinion, investing in PET bottle production could be challenging for the company because we have little knowledge and experience about this process. Why do we need to invest in a new system, when we could easily purchase PET bottles from local suppliers? If the price of the PET bottles is too high, we should consider seeking a new supplier or changing the company's payment policy. We should simplify the process rather than add a new process.

Members of the project team were expected to express their opinions on the three investment options. Before deciding, Minh Le (CEO) hoped that the payback would be two years. Although all three proposals were presented, balancing the economic and environmental performance posed a daunting challenge for managers due to its impacts on the future of the company. At 5:00 pm, they would need to make an official decision about which proposal(s) the company would invest in:

- Proposal 1: Construction of a new system for wastewater treatment, or;

- Proposal 2: Development of a new process for producing PET bottles, or;

- Proposal 3: Acquisition of a new system for the bottle filling process.

\section{Conclusions}

VietGreen identified hotspots and hidden costs by analyzing material and energy flows in both physical and monetary units, thereby identifying three investment proposals (wastewater treatment system, PET bottle production, and bottle filling system). During a meeting in June 2018, members of the MFCA project made a final decision on these investments. The result of this decision had a remarkable influence on enhancing VietGreen's environmental and economic performance.

Recognizing the importance of MFCA in improving decision-making, VietGreen has applied this approach since then. As a result, VietGreen has made continuous improvements in manufacturing activities such as eliminating shrink wraps and producing new products (spark mineral water) with zero-waste. In doing so, it has addressed global environmental challenges such as wastewater pollution, water scarcity, and plastic waste and expressed its 'responsibility and integrity' in the pursuit of the sustainable development goals (SDGs) ${ }^{20}$ such as cleaner water (SDG 6), responsible production (SDG 12), and plastic waste reduction (SDG 14). Overall, VietGreen has become a strong mineral water brand in both local and international markets due to its environmentally friendly products.

\section{Supplementary material}

Supplementary material can be found online at https://doi.org/10.22434/IFAMR2020.0187

\section{Teaching Note.}

Table S1. Global bottled water market consumption by country in 2012 and 2017.

Table S2. Global bottled water market per capita consumption in 2012 and 2017.

Table S3. Total and per capita bottled water consumption in Vietnam 2012-2017.

Table S4. MFCA application project team.

\footnotetext{
${ }^{20}$ https://sdgs.un.org/goals International Food and Agribusiness Management Review
} 
Table S5. The report of chemicals, labelling and packaging materials, and auxiliaries used in 2017.

Table S6. The consumption of electric energy, water, and steam in 2017.

Table S7. The report of wastewater and solid waste in 2017.

Table S8. The report of the pollution volume within $1 \mathrm{~m}^{3}$ wastewater in 2017 .

Table S9. Variable environmental protection fees for wastewater.

Table S10. Price of purchased materials and auxiliaries in 2017.

Table S11. Average electricity price.

Table S12. Natural resource tax.

Table S13. Direct labor salary in 2017.

Table S14. Estimated costs if a new wastewater treatment system would be equipped.

Table S15. Environmental results if a new wastewater treatment system would be equipped.

Table S16. Estimated investment costs for a new system for bottle filling process.

\section{Acknowledgements}

The case study was accepted for a showcase presentation of the 2020 International Food and Agribusiness Management Association World Conference's virtual Teaching Case Workshop. The authors are grateful to three anonymous reviewers for positive and constructive comments. The authors acknowledge open access funding support by the International Food and Agribusiness Management Association and the University of Kassel, Germany.

\section{Conflicts of interest}

The authors declare no conflict of interest.

\section{References}

Asian Productivity Organization (APO). 2014. Manual on material flow cost accounting: ISO 14051. APO, Tokyo, Japan.

Christ, K.L. and R.L. Burritt. 2016. ISO 14051: a new era for MFCA implementation and research. Revista de Contabilidad 19(1): 1-9.

Guenther, E., C. Jasch, M. Schmidt, B. Wagner and P. Ilg. 2015. Material flow cost accounting - looking back and ahead. Journal of Cleaner Production 108: 1249-1254.

Herzig, C., T. Viere, S. Schaltegger and R.L. Burritt. 2012. Environmental management accounting: case studies of South-East Asian companies. Routledge, New York, USA.

International Organization for Standardization (ISO). 2011. ISO 14051: 2011 (en) Environmental management - material flow cost accounting - general framework. Available at: https://www.iso.org/obp/ ui/\#iso:std:iso:14051:ed-1:v1:en

International Organization for Standardization (ISO). 2017. ISO 14052: 2017 Environmental managementmaterial flow cost accounting - guidance for practical implementation in a supply chain. Available at: https://www.iso.org/standard/54811.html

International Organization for Standardization (ISO). 2021. ISO 14053:2021 Environmental managementmaterial flow cost accounting - guidance for practical implementation in organizations. Available at: https://www.iso.org/standard/73338.html

Kokubu, K. and M. Nakajima. 2004. Material flow cost accounting in Japan: a new trend of environmental management accounting practices. In: Fourth Asia Pacific Interdisciplinary Research in Accounting Conference. 4-6 July 2004. Singapore, pp. 1-16.

Ministry of Economy, Trade and Industry (METI). 2010. Material flow cost accounting: MFCA case examples. METI, Tokyo, Japan.

Tran, T.T. and C. Herzig. 2020. Material flow cost accounting in developing countries: a systematic review. Sustainability 12(13): 5413.

Wagner, B. 2015. A report on the origins of material flow cost accounting (MFCA) research activities. Journal of Cleaner Production 108: 1255-1261. 